\title{
Pine dust, atopy and lung function: a cross- sectional study in sawmill workers
}

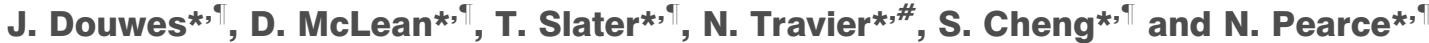

ABSTRACT: An increased risk of asthma symptoms has previously been shown in 772 pine sawmill workers. The aim of the current study was to assess the association between dust exposure, lung function and atopy.

Subjects with $(n=59)$ and without $(n=167)$ asthma symptoms were randomly selected from the previous survey. Lung function and atopy were determined using spirometry and skin-prick tests, respectively. Inhalable dust levels were measured on the same day.

The geometric mean dust concentration was $0.52 \mathrm{mg} \cdot \mathrm{m}^{-3}$. Exposure to dry but not to green dust was associated with asthma symptoms. Green dust was associated with atopic sensitisation, particularly against outdoor allergens; no association was found for dry dust. Forced vital capacity, forced expiratory volume in one second and peak expiratory flow were significantly lower in workers exposed to high levels of green dust $\left(-350 \mathrm{~mL},-260 \mathrm{~mL}\right.$ and $-860 \mathrm{~mL} \cdot \mathrm{s}^{-1}$, respectively) and dry dust $\left(-230 \mathrm{~mL},-190 \mathrm{~mL}\right.$ and $-850 \mathrm{~mL} \cdot \mathrm{s}^{-1}$, respectively). These associations were observed both in subjects with and without asthma symptoms. No associations with crossshift changes in lung function were found.

Exposure to green pine sawdust may be a risk factor for atopy. Both green and dry dust were associated with obstructive as well as restrictive pulmonary effects.

KEYWORDS: Asthma, atopy, lung function, occupational, sawmills, wood dust

W ood and timber processing is a major industry worldwide. Exposure to wood dust originating from a wide range of different tree species is associated with sinonasal cancer and respiratory health effects [1]. Most studies have been conducted in workers processing western red cedar, showing associations between dust exposure and both symptoms and lung function [2]. In a previous study among 772 sawmill workers, it was demonstrated that pine sawmilling was associated with an increased prevalence of asthma and cough symptoms, and eye and nose irritation [3], and several other studies (mainly in furniture workers) have shown similar results [4-6]. In furniture workers, associations between wood dust exposure and both baseline lung function (forced expiratory volume in one second (FEV1)) [4, 7] and reduced crossshift lung function (FEV1) have also been described, with the effects being most pronounced among pine workers $[7,8]$.

Most of the reported respiratory health effects occurred at dust levels well below $5 \mathrm{mg} \cdot \mathrm{m}^{-3}$, an occupational exposure limit (OEL) that is commonly used in many countries, such as New Zealand, Australia and the USA. The European Union Scientific Committee on Occupational
Exposure Limits and the American Conference of Governmental Industrial Hygienists threshold limit value (TLV) committees have both recommended a substantially lower OEL of $1 \mathrm{mg} \cdot \mathrm{m}^{-3}$, and some countries, such as the Netherlands and Denmark, have subsequently lowered the standard to $2 \mathrm{mg} \cdot \mathrm{m}^{-3}$, with the Dutch OEL being based on inhalable dust, compared to total dust in Denmark. Nonetheless, a safe level has so far not been established due to the lack of detailed information on dose-response associations. Currently it is not clear which components of wood dust cause these respiratory health effects. Abietic acid in pine [9] and plicatic acid in western red cedar $[10,11]$ might play a role, but conclusive evidence is lacking. It is also not clear which mechanisms underlie these effects. Some studies found specific immunoglobulin (Ig)E directed against wood dust, but the proportion of symptomatic workers with a positive IgE test result was small $[12,13]$.

In the present study, 167 sawmill workers with and 59 without asthma symptoms were randomly selected from the previous survey [3], and the association between dust exposure and both baseline and cross-shift lung function was assessed. The association between dust exposure
AFFILIATIONS

${ }^{\star}$ Centre for Public Health Research, and,

\#Sleep/Wake Research Centre, Research School of Public Health, Massey University, and

`Wellington Asthma Research Group, Otago University, Wellington, New Zealand

CORRESPONDENCE

J. Douwes

Centre for Public Health Research

Massey University

Private Box 756

Wellington

6002

New Zealand

Fax: 6443800600

E-mail: j.douwes@massey.ac.nz

Received:

October 142005

Accepted after revision:

May 012006

\section{SUPPORT STATEMENT}

The Centre for Public Health Research is supported by a Programme Grant, and J. Douwes by a Sir Charles Hercus Research Fellowship, from the Health Research Council of New Zealand (HRC) (Auckland, New Zealand). This project was supported by a Project Grant from the HRC. 
and atopic sensitisation to common allergens and pine pollen was also studied.

\section{MATERIALS AND METHODS \\ Study design and population}

Phase I of the present study was a cross-sectional questionnaire survey conducted in 772 sawmill workers selected from five large sawmills in New Zealand processing exclusively Pinus radiata [3]. The sawmill process has previously been described in more detail [14]. Subjects with asthma symptoms were defined on the basis of giving at least one positive response to any of the following questions: "Have you been woken up with shortness of breath in the last 12 months?"; "Have you had wheezing in the chest in the last 12 months?"; and "Are you currently taking asthma medication?" [15]. All subjects with asthma symptoms $(n=134)$ and a random sample of subjects without asthma symptoms $(n=200)$ were invited to participate in the current phase II study, $1 \mathrm{yr}$ after the first survey. The same three asthma questions were repeated in phase II, and those who no longer showed symptoms $(n=28)$ were excluded from the asthma group, whereas those who had developed symptoms in the time between the two studies $(n=8)$ were included. An overview of the recruitment, exclusions and refusals is presented in figure 1. Briefly, all night-shift workers and workers who were not available for testing at the time that the sawmill was visited for other reasons (e.g. off-site work activities, no replacement available to take over the work load during the testing period, etc.) were excluded. Participation was declined by $\sim 20 \%$ and a further $15 \%$ had left the work force since the phase I study (these are estimates based on information provided by the site managers). Therefore, it was only possible to include 59 workers with asthma symptoms, and, after replacing 67 of the nonsymptomatic workers who had been excluded or declined participation with the next nonsymptomatic person on the list, it was possible to include 167 nonsymptomatic workers (fig. 1). All subjects gave written informed consent and the study was approved by the Wellington Ethics Committee (protocol 99/ 93) of Wellington Area Health Board.

\section{Exposure assessment}

Full-shift $(8 \mathrm{~h})$ personal inhalable dust exposure was assessed in 205 workers on the same day that lung function and skinprick tests were carried out. Inhalable dust samples were taken at an airflow of $2 \mathrm{~L} \cdot \mathrm{min}^{-1}$, using glass fibre filters mounted in Institute of Occupational Medicine (IOM) sampling heads. Filters were weighed before and after sampling in a climatecontrolled room. Owing to technical errors, 22 samples were excluded. Job-title-based mean exposure levels were used since exposure levels are likely to vary less within job titles than within individuals [16], although associations were also explored using individual exposure levels. Dust exposure categories were constructed by two qualified industrial hygienists with specific experience in this industry, and were based on the workers' work area and job title [3]. Four crude exposure categories were distinguished: 1) nonexposed: administration and other office workers; 2) low or intermittent exposure: yard, maintenance, dispatch and export workers and saw doctors; 3) high exposure to green dust: all workers in the green mill involved in sawing logs to produce green timber, and subsequently sorting, grading, trimming and stacking, and kiln-drying the green timber; and 4) high exposure to dry dust: workers processing kiln-dried timber in the planer mill, remanufacturing and moulding. Dust (including chemicals such as resin acids and monoterpenes) associated with processing fresh timber before it is kiln-dried is referred to as green dust; dust associated with processes that take place after kiln drying is referred to as dry dust.

\section{Skin-prick testing}

Skin-prick tests (Bayer Corporation, West Haven, CT, USA) were carried out on 220 workers at the start of the work shift. Owing to missing values for confounders $(n=8)$, only 212 subjects were used in the adjusted analyses. The solutions tested contained the following allergens (Bayer Corporation): pine pollen mix (lodgepole pine and western yellow pine; ED2204), cat pelt (TR4810), dog hair/dander (ED4084), cockroach (1661603/ED6585), grass mix (1659420/ED2631), mould mix (ED4956), New Zealand/Australian tree pollen mix (oak, beech, birch, plane and ash;1658343) and house dust mite (UP6692/1670858). A positive (histamine) and negative control (diluent) were also tested. After $15 \mathrm{~min}$, the weals were read, and a positive reaction was defined as a weal with a diameter of $\geqslant 3 \mathrm{~mm}$ after subtraction of any reaction to the negative control. The atopy data were also analysed without subtraction of the negative control, but this did not significantly change the results, and, therefore, only the results involving subtraction of the negative control are reported. Two subjects showing no response to the positive control were excluded.

\section{Lung function testing}

Lung function tests were carried out at the beginning and end of the work shift using portable spirometers (Alpha Spirometer; Vitalograph, Buckingham, UK) and with the worker seated in an upright position. Subjects performed three acceptable, reproducible (within 5\%) manoeuvres following standard spirometric procedures [17]. From these, the forced vital capacity (FVC), FEV1 and peak expiratory flow (PEF) were determined. The highest FVC, FEV1 and PEF obtained were used in the analyses. Twelve technically unacceptable lung function tests were excluded. Nine subjects did not reach a maximum FVC, whereas their FEV1 and PEF were acceptable; thus only their FVCs were excluded. In the adjusted analyses, 197 and 206 subjects were used for FVC and FEV1 respectively, due to missing values for confounders $(n=8)$. The results were calculated as a percentage of the predicted value using reference equations described for Caucasians in the USA [18]. Absolute lung function data, adjusted for age, height, sex and ethnicity, were also reported.

\section{Analysis}

Dust concentrations approximated to a lognormal distribution; hence exposure measurements were logarithmically transformed and presented as geometric mean \pm SD. ANOVA was applied to assess the explained variance in dust exposure by exposure category and mill number. Chi-squared and unpaired t-tests were performed in order to test differences in prevalence and mean respectively. Prevalence odds ratios were calculated by means of logistic regression analysis in order to describe the associations between exposure and atopy, and exposure and asthma symptoms. The association between exposure and lung function was calculated using linear 


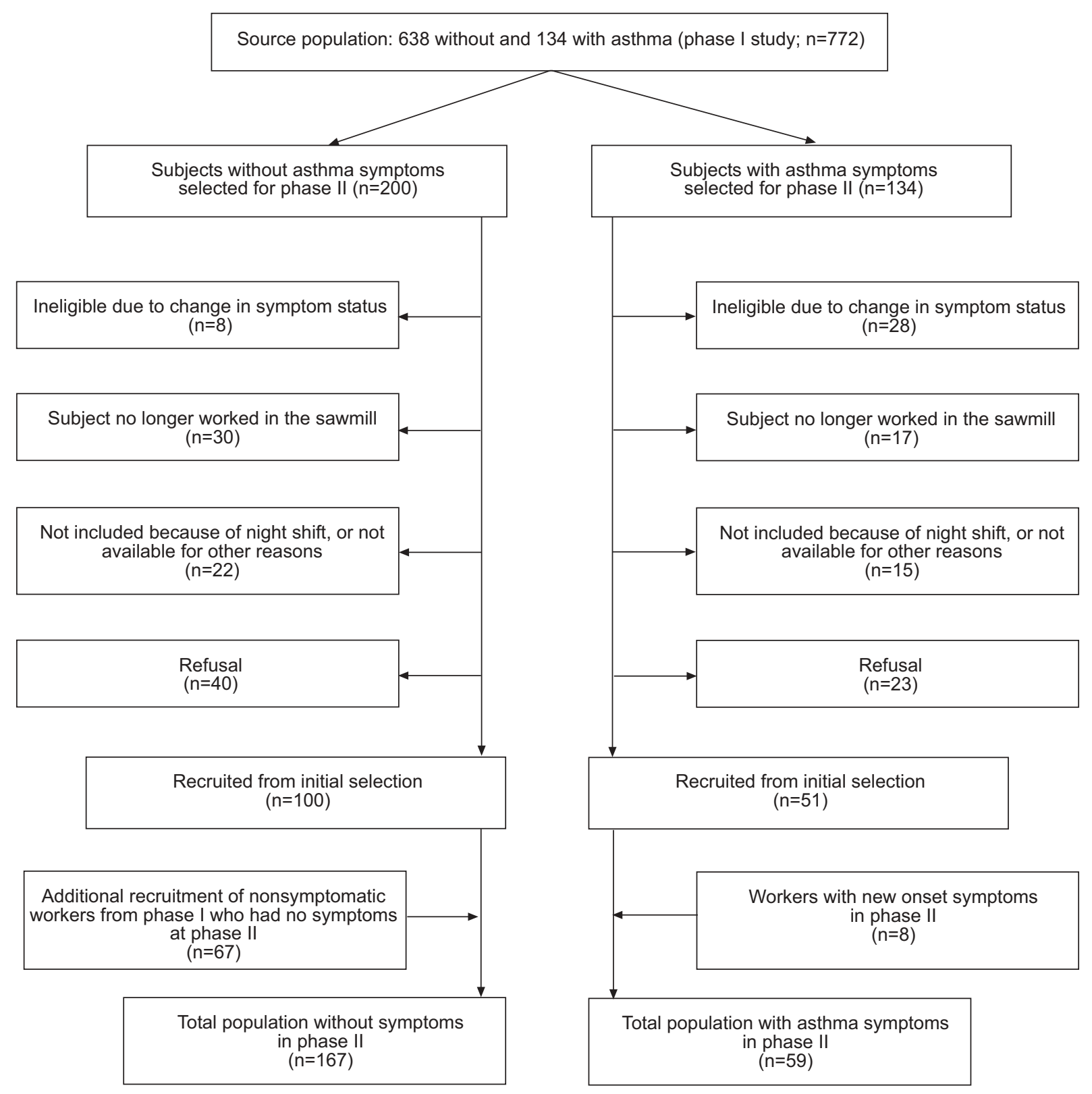

FIGURE 1. Flow diagram showing subject recruitment, exclusion and refusals. Phase II participants were approached through the sawmill site managers directly; the number of workers in each category was, therefore, estimated based on the information provided by the site managers. All night-shift workers and workers who were not available for testing at the time that the sawmill was visited for other reasons (e.g. off-site work activities, no replacement available to take over the work load during the testing period, etc.) were excluded.

regression analysis, with analyses adjusted for age, sex, current and previous smoking, ethnicity and height. All analyses involving outcome variables other than asthma symptoms were also adjusted for the occurrence of asthma symptoms. Analyses were also stratified based on the occurrence of asthma symptoms in order to test for homogeneity.

\section{RESULTS}

The geometric mean $\pm \mathrm{SD}$ dust concentration for all workers was $0.52 \pm 2.66 \mathrm{mg} \cdot \mathrm{m}^{-3}(\mathrm{n}=183)$. The mean dust levels for each exposure group corroborated the previous exposure assessment based on expert judgement; however, the variance in exposure within each group was substantial (table 1). Since the number of workers in the nonexposed group was very low $(n=20)$, they were combined with the low/intermittent exposure group, resulting in a significant reduction in the explained variance (14 versus $26 \%$; table 1 ). The non-/low/ intermittent exposure group was subsequently used as the reference group for all further analyses.

Significant differences in age, smoking, ethnicity, time worked outdoors and use of respiratory equipment were observed among the non/low/intermittent, high dry and high green dust exposure groups (table 2). The population characteristics of subjects with and without asthma symptoms were very similar (table 2). 


\begin{tabular}{lcc} 
TABLE 1 & $\begin{array}{c}\text { Dust concentrations stratified by job-title-defined } \\
\text { exposure category }\end{array}$ \\
& $\begin{array}{c}\text { Subjects } \\
\mathbf{n}\end{array}$ & $\begin{array}{c}\text { Dust } \\
\mathbf{m g} \cdot \mathbf{m}^{-3}\end{array}$ \\
\hline Non-/low/intermittent exposure & 92 & $0.38 \pm 2.80(0.02-4.51)$ \\
$\quad$ Nonexposed & 20 & $0.15 \pm 2.44(0.02-0.62)$ \\
Low/intermittent exposure & 72 & $0.49 \pm 2.48(0.06-4.51)$ \\
High exposure to dry dust & 48 & $0.62 \pm 2.23(0.08-3.11)$ \\
High exposure to green dust & 43 & $0.80 \pm 2.25(0.24-6.24)$ \\
\hline
\end{tabular}

Data are presented as geometric mean \pm SD (range). The ANOVA-explained variance including four exposure categories and mill number was $26 \%$ $(p<0.0001)$, and including three exposure categories (combining nonexposed and low/intermittent exposure) and mill number was $14 \%(p<0.0001)$

High exposure to dry dust was associated with asthma symptoms (adjusted odds ratio (OR) 2.1; 95\% confidence interval (CI) 1.0-4.4), whereas no association with high green dust exposure (adjusted OR 1.4; 95\% CI 0.6-3.3) was found. Atopy, defined as a positive skin-prick test result with one or more of the tested allergens, was very common $(80 \%$ in subjects with and $50 \%$ in those without asthma symptoms). Of the subjects, $6 \%$ were sensitised against pine pollen and $20 \%$ against the tree pollen mix. No significant association between sensitisation against pine or other tree pollen (mix) and asthma symptoms was observed (data not shown). High exposure to green dust was significantly associated with atopic sensitisation against outdoor allergens (pine, grass mix or tree mix) and to a lesser extent with sensitisation against indoor allergens (mould, cockroach, dust mite, dog and cat) (fig. 2). The strongest association was found with atopy when defined as $\geqslant 2$ or $\geqslant 3$ positive skin prick test results with adjusted ORs of
2.6 and 3.1 , respectively $(\mathrm{p}<0.05)$. High exposure to dry dust was not associated with atopy (fig. 2).

Subjects with asthma symptoms exhibited a significantly lower FEV1 and PEF than those without asthma symptoms, whereas their FVC was very similar (table 3).

High exposure to both dry and green dust were significantly associated with a reduction in FEV1 $(-190$ and $-260 \mathrm{~mL}$, respectively) and PEF (-850 and $-860 \mathrm{~mL} \cdot \mathrm{s}^{-1}$, respectively) (table 4$)$. The FVC was also reduced $(-230$ and $-350 \mathrm{~mL}$, respectively), significant in the high green dust exposure group and borderline significant for the high dry dust

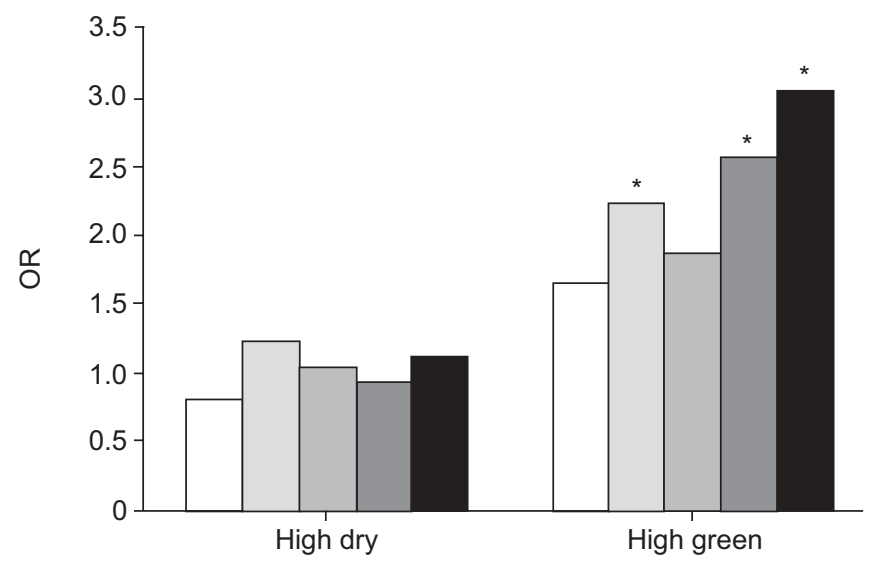

FIGURE 2. Association between exposure and several definitions of atopy Indoor $(\square ; n=212)$ and outdoor atopy $(\square ; n=212)$ were defined as any positive skin-prick test (SPT) result with any of the indoor (mould mix, cockroach, dust mite, dog, cat) or outdoor allergens (pine, grass mix, tree mix), respectively ( $\square: \geqslant 1$ SPT $(\mathrm{n}=212) ; \mathbf{\square}: \geqslant 2$ SPTs $(\mathrm{n}=161) ; \mathbf{\square}: \geqslant 3$ SPTs $(\mathrm{n}=133)$ ). Odds ratios (ORs) were adjusted for symptom status, sex, age, ethnicity and smoking. *: $p<0.05$

TABLE 2 Characteristics of study population stratified by exposure and asthma symptom status

\begin{tabular}{|c|c|c|c|c|c|}
\hline & Non/low/intermittent & High dry & High green & Absent & Present \\
\hline Subjects $\mathrm{n}$ & $117^{\bullet}$ & $53^{+}$ & $56^{\S}$ & 167 & 59 \\
\hline Age yrs & $39.8 \pm 11.0$ & $34.3 \pm 10.3^{\star \star}$ & $35.3 \pm 11.8^{\star}$ & $37.5 \pm 11.2$ & $37.3 \pm 11.5$ \\
\hline Time in current sawmill yrs & $9.9 \pm 8.5$ & $7.1 \pm 7.2^{\star}$ & $8.1 \pm 7.2$ & $8.8 \pm 8.0$ & $8.9 \pm 7.9$ \\
\hline Smokers \% & 30.2 & 28.8 & $56.6^{* \star}$ & 37.4 & 32.8 \\
\hline Ex-smokers \% & 31.0 & 23.1 & 20.8 & 28.8 & 20.7 \\
\hline Female \% & 19.8 & 25.0 & 13.2 & 19.6 & 19.0 \\
\hline Maori $^{\#} \%$ & 19.0 & $35.3^{*}$ & $49.1^{* \star}$ & 31.3 & 26.3 \\
\hline Pacific Islander $\%$ & 6.9 & 2.0 & $24.5^{* \star}$ & 9.2 & 12.3 \\
\hline
\end{tabular}

Data are presented as mean $\pm \mathrm{SD}$ or percentages. ${ }^{*}$ : question allowed for multiple ethnic identification; ${ }^{\bullet}$ : one missing for some variables; ${ }^{+}$: three missing for some variables; s: one or two missing for some variables. *: $p<0.05$; ${ }^{* *}: p<0.01$ versus nonexposed group. 


\begin{tabular}{|c|c|c|c|}
\hline \multirow[t]{3}{*}{ TABLE 3} & \multicolumn{3}{|c|}{$\begin{array}{l}\text { Baseline lung function for subjects with and } \\
\text { without asthma symptoms. }\end{array}$} \\
\hline & \multicolumn{2}{|c|}{ Asthma symptoms } & \multirow[t]{2}{*}{ Difference $(95 \% \mathrm{Cl})^{\#}$} \\
\hline & Absent & Present & \\
\hline \multicolumn{4}{|l|}{ FVC } \\
\hline L & $4.61 \pm 1.04$ & $4.49 \pm 1.12$ & $-0.04(-0.25-0.18)$ \\
\hline$\%$ pred & $91.72 \pm 14.18$ & $89.50 \pm 13.55$ & $-1.19(-5.43-3.04)$ \\
\hline \multicolumn{4}{|l|}{$\mathrm{FEV}_{1}$} \\
\hline L & $3.59 \pm 0.87$ & $3.24 \pm 0.91$ & $-0.31(-0.48--0.14)^{\star \star}$ \\
\hline$\%$ pred & $87.80 \pm 13.85$ & $79.31 \pm 14.91$ & $-7.86(-11.85--3.87)^{\star \star}$ \\
\hline \multicolumn{4}{|l|}{ PEF } \\
\hline$L \cdot S^{-1}$ & $8.75 \pm 2.28$ & $7.56 \pm 2.04$ & $-1.12(-1.65--0.59)^{\star \star}$ \\
\hline$\%$ pred & $91.84 \pm 18.99$ & $79.43 \pm 17.06$ & $-11.61(-17.17--6.05)^{\star \star}$ \\
\hline
\end{tabular}

Data are presented as mean \pm SD. Adjusted analyses were based on 197 subjects for forced vital capacity (FVC) and 206 for forced expiratory volume in one second (FEV1) and peak expiratory flow (PEF). Cl: confidence interval; \% pred: percentage of the predicted value. ${ }^{\#}$ : adjusted for sex, age, ethnicity, smoking and height. ${ }^{*}: \mathrm{p}<0.01$

exposure group. Similar results were obtained when lung function was expressed as a percentage of the predicted value (table 4). Stratified analyses indicated that the effects in subjects with asthma symptoms were somewhat stronger for high dry dust exposure, whereas they were somewhat weaker for high green dust exposure (table 4). Nonetheless, results were quite similar, suggesting no strong heterogeneity, perhaps with the exception of FVC in the high-green-dustexposed, in whom the effect appears to be driven by the subjects with no asthma symptoms. Additional adjustments for use of personal respiratory protective equipment or mill number did not alter the results. Cross-shift changes (adjusted for height, age, sex and other confounders) in FEV1 and PEF were slightly lower in the high-dry- and high-green-dustexposed workers $\left(-40 \mathrm{~mL}\right.$ and -110 and $-150 \mathrm{~mL} \cdot \mathrm{s}^{-1}$, respectively), but these differences were not significant. No associations were found between exposure and FEV1/FVC, and exposure and the number of subjects with a FEV1/FVC of $<70 \%$ (a key parameter in the diagnosis of chronic obstructive pulmonary disease). Also, no associations with any of the lung function parameters were found using individual exposure measurements.

\section{DISCUSSION}

In this cross-sectional study, sawmill workers exposed to high levels of green pine dust were more likely to be atopic than those who received low or no exposure. In addition, both dry and green pine dust exposure were associated with reduced baseline lung function. No clear acute cross-shift lung function effects were observed.

As workers with asthma symptoms were over-sampled, more weight was effectively given to symptomatic workers, and the analyses for other health outcomes were therefore adjusted for symptom status. The effect of over-sampling subjects with asthma symptoms was very small, as demonstrated by the fact that exposure-related lung function deficits calculated separately for subjects with and without asthma symptoms were only moderately different (table 4). In addition, when the analyses for exposure and atopy were stratified by symptom status, there was no evidence of heterogeneity between subjects with and without asthma symptoms (data not shown).

For practical reasons, it was possible to recruit only 59 (52\%) of the 114 eligible symptomatic workers (fig. 1), potentially

Differences in baseline lung function between high and non/low/intermittent exposure in subjects with and without asthma symptoms ${ }^{\#}$

\begin{tabular}{|c|c|c|c|c|c|c|}
\hline & \multicolumn{3}{|c|}{ High dry dust exposure } & \multicolumn{3}{|c|}{ High green dust exposure } \\
\hline & Total & No asthma symptoms & Asthma symptoms & Total & No asthma symptoms & Asthma symptoms \\
\hline Subjects $\mathbf{n}$ & 50 & 32 & 18 & 50 & 37 & 13 \\
\hline $\begin{array}{l}\text { Reference } \\
\text { category } \mathbf{n} \\
\text { FVC }\end{array}$ & 156 & 114 & 42 & 156 & 119 & 37 \\
\hline$\%$ pred & $-3.57(-8.28-1.13)$ & $-3.70(-9.46-2.07)$ & $-2.31(-11.52-6.90)$ & $-6.33(-11.33--1.33)^{*}$ & $-8.08(-14.18--1.99)^{*}$ & $-1.07(-11.33-9.19)$ \\
\hline \multicolumn{7}{|l|}{ FEV 1} \\
\hline L & $-0.19(-0.37-0.00)^{\star}$ & $-0.14(-0.36-0.08)$ & $-0.24(-0.57-0.10)$ & $-0.26(-0.46--0.06)^{*}$ & $-0.21(-0.44-0.03)$ & $-0.23(-0.60-0.15)$ \\
\hline$\%$ pred & $-3.89(-8.35-0.57)$ & $-2.90(-8.16-2.36)$ & $-5.00(-13.17-3.16)$ & $-5.72(-10.56--0.88)^{\star}$ & $-5.18(-10.88-0.52)$ & $-3.36(-12.56-5.83)$ \\
\hline \multicolumn{7}{|l|}{ PEF } \\
\hline$L \cdot S^{-1}$ & $-0.85(-1.43--0.26)^{\star *}$ & $-0.79(-1.53--0.05)^{\star}$ & $-0.96(-1.89--0.03)$ & $-0.86(-1.50--0.23)^{\star \star}$ & $-0.96(-1.76--0.16)^{*}$ & $-0.53(-1.58-0.52)$ \\
\hline
\end{tabular}

Data are presented as mean (95\% confidence interval). Analyses were adjusted for symptom status (with the exception of the stratified analyses), sex, age, ethnicity, smoking and height. FVC: forced vital capacity; FEV1: forced expiratory volume in one second; PEF: peak expiratory flow; \% pred: percentage of the predicted value. \# subjects with high dust exposure were compared to the reference categories which consisted of all non/low/intermittent exposure workers. $\because$ : nine subjects had missing FVC values (see Lung function testing section). *: $p<0.05 ;{ }^{*}: p<0.01$. 
introducing nonresponse bias. However, it was considered that the potential for nonresponse bias was minimal for the following reasons: 1) no significant differences in symptom severity, exposure, age, smoking and ethnicity were found between workers with asthma symptoms included in the first and second phases of the study (data not shown); 2) similar associations between wood dust exposure and lung function were found for workers with and without asthma symptoms; and 3) in those workers whom it was possible to contact for the second phase of the study, the response rate was high $(\sim 80 \%)$; similarly, the response rate was high for the nonsymptomatic workers whom it was possible to contact for the phase II study (fig. 1).

Group-mean exposure categories have previously been shown to result in less biased exposure estimates in the wood processing industry $[8,13,16]$. Nonetheless, in the present study, the exposure categories were relatively crude, with a relatively large variance in concentrations within each exposure group (table 1). Owing to low numbers in the nonexposed group, it was necessary to combine this group with the low/ intermittent exposure group, further reducing the contrasts between the exposure categories. This could explain why, compared to the previous survey (in which a reference group of exclusively nonexposed workers was used [3]), weaker relationships were found between exposure and asthma symptoms. Current exposures were also used to estimate group means, whereas cumulative or past exposures may have been more relevant. Unfortunately it was not possible to explore this since no detailed information was available concerning past exposures and/or job titles. The duration of employment in the current sawmill was inversely associated with lung function, but, compared to current group-meanbased exposures (based on job title and work area), the effects were small (data not shown). Job title and area may therefore, in the present study, be a better predictor of cumulative exposure than duration of employment. Finally, dust may not be the best marker of the true causal exposures, since abietic acid, monoterpenes or microbial agents may be more important [19]. All of the above issues may have resulted in random exposure misclassification, but this is likely to have produced a bias towards the null hypothesis and is unlikely to explain the present positive findings [20].

Adjustments were made for potential confounders in the multivariate analyses and did not change the results, with the exception of ethnicity. Since Polynesians (Maori and Pacific Islanders) exhibit lower mean lung function [21, 22], and the adjusted and unadjusted analyses differed, a further check was performed by repeating the analyses of lung function excluding all non-European New Zealanders. These analyses showed similar results, i.e. lung function was reduced in both the high dry dust exposure group (FVC $370 \mathrm{~mL}$ (95\% CI -670- -70 mL; $\mathrm{p}=0.018)$; FEV1 $-320 \mathrm{~mL}(95 \% \mathrm{CI}-540--100 \mathrm{~mL} ; \mathrm{p}=0.005)$; and PEF $-1,460 \mathrm{~mL} \cdot \mathrm{s}^{-1}\left(95 \%\right.$ CI 2,100- $\left.\left.-820 \mathrm{~mL} \cdot \mathrm{s}^{-1} ; \mathrm{p}=0.0001\right)\right)$ and the high green dust exposure group (FVC $-220 \mathrm{~mL}(95 \% \mathrm{CI}$ 640-210 mL; $\mathrm{p}=0.320) ; \mathrm{FEV} 1-140 \mathrm{~mL}(95 \% \mathrm{CI}-450-180 \mathrm{~mL}$; $\mathrm{p}=0.396)$; and PEF $-620 \mathrm{~mL} \cdot \mathrm{s}^{-1}\left(95 \%\right.$ CI $1,550-300 \mathrm{~mL} \cdot \mathrm{s}^{-1}$; $\mathrm{p}=0.178)$ ). This indicates that the present results did not arise due to confounding by ethnicity. The lack of significance for the associations with green dust can be explained by the low number of subjects after excluding all Polynesians.
Baseline lung function in the reference group was lower than expected based on the predicted values. This may be because the reference group was also exposed to significant levels of dust (table 1), or the fact that a significant proportion were Polynesians, who are known to exhibit lower lung function than Caucasians (see above). Also, the predicted values were based on a US population [18], which may not reliably predict lung function in New Zealanders. In any case, consistent associations were found, which were highly comparable with the results based on the measured lung function, indicating that the reported results are valid.

Elevated exposures to both dry and green pine dust were associated with a significant deficit in baseline lung function, of both an obstructive (FEV1 and PEF) and restrictive (FVC) nature. This is consistent with previous findings in sawmill workers processing western red cedar [2, 23] and pine [5], although some studies in pine sawmill workers showed no effects on FVC and FEV1 [24, 25]. Reduced FEV1 and FVCs have also been reported for furniture workers exposed to dry pine dust $[4,7]$. Pine dust exposure in furniture making was shown to be more potent at affecting lung function than other types of wood [7]. In the present study, the effect of dry dust exposure on FVC appeared to be driven mainly by the subjects without asthma symptoms (table 4); the reasons for this are not clear. In contrast to other studies [7,8], no significant effects on cross-shift lung function were found. Small changes in crossshift lung function may not have been detectable in the present study because of the already substantially reduced baseline lung function in the high exposure subjects.

Atopy is not generally used as an outcome variable in occupational asthma studies. Nonetheless, several recent studies have shown that certain exposures may offer protection against atopy (e.g. occupational endotoxin exposure [26]), whereas others have shown that exposures such as diesel exhaust may increase the risk of atopy [27]. The present study is the first to show a positive association between pine dust exposure and atopy. A previous study in western red cedar workers showed a lower prevalence of atopy compared to nonexposed controls [23]. Qualitative and quantitative differences in exposure may explain these contradictory findings. Several studies have demonstrated $\operatorname{IgE}$ responses against various types of wood including pine $[12,13]$. However, in most of these studies, only few workers showed positive responses [12]. Allergy to pine dust is, therefore, unlikely to explain the elevated prevalence of atopy in the workers exposed to high levels of green dust. Also, it is unlikely to be related to pollen exposure, since the pine pollen skin-prick test results were not associated with exposure (data not shown). Since an association was only found with green dust, it is more likely to be related to agents, such as resin acids or monoterpenes, which are present at elevated levels during pine processing, particularly in areas in which fresh wood is sawn [28]. These agents may either be allergenic themselves following oxidation [29] or possibly act as adjuvants, increasing the risk of becoming allergic to other agents. Microbial agents present in the sapwood of fresh pine logs may also play a role [30].

Whether or not atopic mechanisms can explain the increased risk of asthma symptoms and adverse lung function effects 
remains unclear. It is of interest to note that, in the current study, the effect on asthma symptoms was found in the high dry dust exposure group, whereas the effect on atopy was observed in the high green dust exposure group, and effects on baseline lung function were found in both the high green dust and high dry dust exposure categories. This suggests that, in the present population, the underlying mechanisms and/or causal exposures might be different for atopy, asthma symptoms and lung function.

The effects observed in the current study occurred at mean levels $\left(0.6-0.8 \mathrm{mg} \cdot \mathrm{m}^{-3}\right)$ well below the current occupational exposure standard $\left(5 \mathrm{mg} \cdot \mathrm{m}^{-3}\right)$ used in most countries (table 1 ). This finding is in line with other studies $[7,8]$ and suggests that the standard may be too high, as suggested previously [1].

In conclusion, exposure to pine wood dust, and/or specific components therein, may increase the risk of atopy and obstructive and restrictive pulmonary effects.

\section{ACKNOWLEDGEMENTS}

The authors are indebted to the management and workers of the sawmills for their participation. The authors also thank J. Campbell, C. Downs, S. Holt, S. Easthope and A. Zacharasiewicz for their assistance in the data collection.

\section{REFERENCES}

1 Demers PA, Teschke K, Kennedy SM. What to do about softwood? A review of respiratory effects and recommendations regarding exposure limits. Am J Ind Med 1997; 31: 385-398.

2 Noertjojo HK, Dimich-Ward H, Peelen S, Dittrick M, Kennedy SM, Chan-Yeung M. Western red cedar dust exposure and lung function: a dose-response relationship. Am J Respir Crit Care Med 1996; 154: 968-973.

3 Douwes J, McLean D, Slater T, Pearce N. Asthma and other respiratory symptoms in New Zealand pine processing sawmill workers. Am J Ind Med 2001; 39: 608-615.

4 Shamssain MH. Pulmonary function and symptoms in workers exposed to wood dust. Thorax 1992; 47: 84-87.

5 Mandryk J, Alwis KU, Hocking AD. Effects of personal exposures on pulmonary function and work-related symptoms among sawmill workers. Ann Occup Hyg 2000; 44: 281-289.

6 Schlunssen V, Schaumburg I, Heederik D, Taudorf E, Sigsgaard T. Indices of asthma among atopic and nonatopic woodworkers. Occup Environ Med 2004; 61: 504-511.

7 Schlunssen V, Schaumburg I, Taudorf E, Mikkelsen AB, Sigsgaard T. Respiratory symptoms and lung function among Danish woodworkers. J Occup Environ Med 2002; 44: 82-98.

8 Schlunssen V, Sigsgaard T, Schaumburg I, Kromhout H. Cross-shift changes in FEV1 in relation to wood dust exposure: the implications of different exposure assessment methods. Occup Environ Med 2004; 61: 824-830.

9 Ayars GH, Altman LC, Frazier CE, Chi EY. The toxicity of constituents of cedar and pine woods to pulmonary epithelium. J Allergy Clin Immunol 1989; 83: 610-618.

10 Chan-Yeung M. Mechanism of occupational asthma due to western red cedar (Thuja plicata). Am J Ind Med 1994; 25: 13-18.
11 Obata H, Dittrick M, Chan H, Chan-Yeung M. Sputum eosinophils and exhaled nitric oxide during late asthmatic reaction in patients with western red cedar asthma. Eur Respir J 1999; 13: 489-495.

12 Skovsted TA, Schlunssen V, Schaumburg I, Wang P, StaunOlsen P, Skov PS. Only few workers exposed to wood dust are detected with specific IgE against pine wood. Allergy 2003; 58: 772-779.

13 Schlunssen V, Skovsted TA, Schaumburg I, Skov PS, Sigsgaard T. Wood dust sensitization among Danish woodworkers. Am J Ind Med 2004; 46: 408-409.

14 Douwes J, McLean D, van der Maarl E, Heederik D, Pearce N. Worker exposures to airborne dust, endotoxin and $\beta(1,3)$-glucan in two New Zealand sawmills. Am J Ind Med 2000; 38: 426-430.

15 Burney PG, Luczynska C, Chinn S, Jarvis D. The European Community Respiratory Health Survey. Eur Respir J 1994; 7: 954-960.

16 Teschke K, Spierings J, Marion SA, Demers PA, Davies HW, Kennedy SM. Reducing attenuation in exposure-response relationships by exposure modeling and grouping: The relationship between wood dust exposure and lung function. Am J Ind Med 2004; 46: 663-667.

17 American Thoracic Society, Standardization of Spirometry, 1994 Update. Am J Respir Crit Care Med 1995; 152: 1107-1136.

18 Hankinson JL, Odencrantz JR, Fedan KB. Spirometric reference values from a sample of the general U.S. population. Am J Respir Crit Care Med 1999; 159: 179-187.

19 Demers PA, Teschke K, Davies HW, Kennedy SM, Leung V. Exposure to dust, resin acids, and monoterpenes in softwood lumber mills. AIHAJ 2000; 61: 521-528.

20 Pearce N, Beasley R, Burgess C, Crane J. Asthma Epidemiology: Principles and Methods. New York, NY, Oxford University Press, 1998.

21 de Hamel FA, Welford B. Lung function in Maoris and Samoans working in New Zealand. N Z Med J 1983; 96: 560-562.

22 Neukirch F, Chansin R, Liard R, Levallois M, Leproux P. Spirometry and maximal expiratory flow-volume curve reference standards for Polynesian, European, and Chinese teenagers. Chest 1988; 94: 792-798.

23 Chan-Yeung M, Vedal S, Kus J, MacLean L, Enarson D, Tse KS. Symptoms, pulmonary function, and bronchial hyperreactivity in western red cedar workers compared with those in office workers. Am Rev Respir Dis 1984; 130: 1038-1041.

24 Malmberg PO, Rask-Andersen A, Larsson KA, Stjernberg N, Sundblad BM, Eriksson K. Increased bronchial responsiveness in workers sawing Scots pine. Am J Respir Crit Care Med 1996; 153: 948-952.

25 Eriksson KA, Stjernberg NL, Levin JO, Hammarstrom U, Ledin MC. Terpene exposure and respiratory effects among sawmill workers. Scand J Work Environ Health 1996; 22: 182-190.

26 Portengen L, Preller L, Tielen M, Doekes G, Heederik D. Endotoxin exposure and atopic sensitization in adult pig farmers. J Allergy Clin Immunol 2005; 115: 797-802. 
27 Janssen NAH, Brunekreef B, Van Vliet P, Aarts F, Meliesfste K, Harssema $H$. The relationship between air pollution from heavy traffic and allergic sensitization, bronchial hyperresponsiveness, and respiratory symptoms in Dutch schoolchildren. Environ Health Perspect 2003; 111: 1512-1518.

28 Teschke K, Demers PA, Davies HW, Kennedy SM, Marion SA, Leung V. Determinants of exposure to inhalable particulate, wood dust, resin acids, and monoterpenes in a lumber mill environment. Ann Occup Hyg 1999; 43: 247-255.

29 Smith PA, Gardner DR, Drown DB, Jederberg WW, Still K. Oxidized resin acids in aerosol derived from rosin core solder. Am Ind Hyg Assoc J 1998; 59: 889-894.

30 Skorska C, Krysinska-Traczyk E, Milanowski J, et al. Response of furniture factory workers to workrelated airborne allergens. Ann Agric Environ Med 2002; 9: 91-97. 